\title{
CHARACTERIZATION OF ICE RECRYSTALLIZATION IN ICE CREAM DURING STORAGE USING THE FOCUSED BEAM REFLECTANCE MEASUREMENT
}

\author{
F. T. NDOYE*, G. ALVAREZ \\ Irstea, Refrigeration Process Engineering Research Unit \\ 1 rue Pierre-Gilles de Genes CS10030, F-92761Antony Cedex, France \\ *Fax: +33 1 40966475, fatou-toutie.ndoye@irstea.fr
}

\begin{abstract}
Ice recrystallization was investigated in two commercial and differently formulated ice creams using a rapid and real time granulometric method: the focused beam reflectance measurement. Ice cream A (with locust bean gum as primary stabilizer) and ice cream B (with carrageenan as primary stabilizer) were stored for 154 days at four different temperatures $\left(-5,-8,-12\right.$ and $\left.-18^{\circ} \mathrm{C}\right)$ and three amplitudes of temperature fluctuations $\left( \pm 0.1^{\circ} \mathrm{C}, \pm 0.75^{\circ} \mathrm{C}, \pm 2.5^{\circ} \mathrm{C}\right)$. Crystal size distribution was assessed at regular time intervals and recrystallization kinetic data was derived by fitting the experimental results to the asymptotic Ostwald ripening model. As expected, recrystallization rates increase with mean storage temperature and amplitude of temperature fluctuations. Carrageenan seems to be more effective than LBG in slowing down ice crystal growth during storage. Mean ice crystal size increased as a function of time $e^{1 / 3}$ for both ice creams. The temperature dependence of recrystallization rate fitted Arrhenius well, with activation energies fairly similar for both ice creams.
\end{abstract}

\section{INTRODUCTION}

Ice recrystallization phenomena are of major concern in the cold chain of frozen desserts, such as ice cream, due to quality loss problems. Ice recrystallization is promoted by fluctuating temperatures but can also occur at constant temperature during long-term storage, leading to an increase in the ice crystals size. In case of ice cream, ice crystals can become so large that they can be detected in the mouth, inducing an unacceptable coarse and grainy taste and texture for the consumer. There are several recrystallization mechanisms among which, migratory recrystallization (also called Ostwald ripening) have been identified to be predominant during ice cream storage (Donhowe and Hartel, 1996a). It is characterized by the growth of large crystals at the expense of the small ones due to the difference in equilibrium temperature caused by surface energy contributions. Donhowe and Hartel (1996a; 1996b) studied the effect of the storage at constant and fluctuating temperatures on ice recrystallization in ice cream. They showed that ice recrystallization increased with the increasing temperature and with the increasing extent of temperature fluctuation. They reported that the mean size of

$3^{\text {rd }}$ IIR International Conference on Sustainability and the Cold Chain, London, UK, 2014 
ice crystals increased with time ${ }^{1 / 3}$ describing the recrystallization process with an asymptotic model called Ostwald ripening equation (eq. (1)) based on the theory of Lifshitz, Slyozov, and Wagner:

$$
\bar{L}(t)=\bar{L}_{0}+k t^{1 / n}
$$

The extent of recrystallization during the storage is also influenced by the formulation of the food system. Among the ingredients of ice cream, it was recognized that stabilizers have an important impact on ice recrystallization by reducing the rate of growth of ice crystals during storage and handling throughout the cold chain (Caldwell et al., 1992; Flores and Goff, 1999). Despite of the various studies, there is no consensus on the mechanism by which the stabilizers limit or inhibit the ice recrystallization. However, most of the authors attributed the mechanism to an increased viscosity of the unfrozen phase slowing down water molecular mobility (Caldwell et al., 1992; Regand and Goff, 2003; Hagiwara et al., 2009).

Most of the studies related to the measurement of the recrystallization rate by determining the ice crystals size distribution and ice crystals mean size deals with microscopy and image analysis (Donhowe and Hartel, 1996a; Donhowe and Hartel, 1996b; Regand and Goff, 2003; Aleong et al., 2008). This two steps procedure (microscopic visualization then image analysis) has proven its efficacy but the technique is cumbersome and time consuming. Thus, it can be useful to have a more automated measurement technique able to provide results faster. This can be done with the focused beam reflectance measurement (FBRM), a real time method of counting and sizing which application in food processes is not very widespread and is still innovative (Arellano et al., 2012; Ndoye et al., 2013). The FBRM technology returned chord length distributions (CLD) based on light backscattering using a revolving laser beam. FBRM technique can considerably reduce the measurement and the post-treatment times required to characterize recrystallization phenomena, in comparison with microscopic techniques.

The general purpose of this work was to study the effect of mean storage temperature and temperature oscillations on ice recrystallization in two differently formulated ice creams using the FBRM. The instrument was utilized to characterize and to follow changes in ice crystal size over time. The asymptotic Ostwald ripening model was fitted to the experimental results obtained under a wide range of storage conditions and recrystallization kinetic data was derived in order to enable the prediction of ice crystals size along the cold chain.

\section{MATERIALS AND METHODS}

\subsection{Ice cream}

Two different commercial vanilla ice creams provided by producers were used in this work: ice cream A (ICA) and ice cream B (ICB). They were delivered directly from the industrial platform just after their production. The same blend of stabilizers (carrageenan, locust bean gum and guar gum) was used in both ice creams, but with different proportions. In ICA, locust bean gum was used as primary stabilizer followed by guar gum and finally carrageenan. Contrariwise, 
carrageenan was the primary stabilizer in ICB, followed by locust bean gum and finally guar gum. It is important to note that this latter formulation is particular because carrageenan is usually rather used as a secondary stabilizer to prevent phase separation. Ice creams were packaged in plastic container of $1 \mathrm{~L}$.

\subsection{Controlled storage freezers and storage treatments}

Four horizontal freezers (Electrolux ECM30132W), with an internal volume of 292 $\mathrm{L}$ for each, were used for the storage of ice cream containers. Each of the four freezers was set at a mean temperature $\left(-5,-8,-12\right.$ and $\left.-18^{\circ} \mathrm{C}\right)$ and was separated in three parts of equal volume ( $90 \mathrm{~L}$ for each one), more or less insulated, in order to make three different amplitudes of temperature fluctuations $\left( \pm 0.1^{\circ} \mathrm{C}, \pm 0.75^{\circ} \mathrm{C}\right.$ and $\pm 2.5^{\circ} \mathrm{C}$ ) These conditions were chosen to be simulate those which could be encountered in cold chain. Ice cream containers (12 ICA and 6 ICB for each compartment of each freezer) were stored during 154 days. 'Control' containers were stored in a cold room at $-30^{\circ} \mathrm{C}$ for the duration of the experiments. Temperatures at the centre and at the top surface of the ice cream inside the container and air temperature throughout compartments were continuously recorded during storage experiments.

\subsection{FBRM ice crystal size analysis}

Periodically, ice cream samples were analyzed to characterize the ice crystal size distributions and then the recrystallization rate was determined. Before ice crystal size measurements, ice cream containers were equilibrated at $-15^{\circ} \mathrm{C}$ for about 25 hrs. All equipments used for further treatment of the samples were precooled at $15^{\circ} \mathrm{C}$. Approximately $60 \mathrm{~mL}$ of ice cream was sampled at the centre of each container using an insulated bottle and a cooled spoon. Sampling was done inside the freezer and sample was immediately diluted at $-15^{\circ} \mathrm{C}$ in $30 \mathrm{~mL}$ of silicone oil (50 cP of viscosity) placed in a thermo-regulated bath. For all conditions, samples were prepared from 2 different containers to obtain results in duplicate.

Analyses were performed at $-15^{\circ} \mathrm{C}$ with the Lasentec ${ }^{\circledR}$ FBRM S400-8 (Mettler Toledo USA) device. The FBRM instrument is composed of a measurement probe, an electronic measurement unit and a computer for data acquisition and analysis. The probe, in stainless steel, has an external diameter of $9.5 \mathrm{~mm}$ and a length of $120 \mathrm{~mm}$. The laser beam is projected through the sapphire window at a wavelength of $780 \mathrm{~nm}$. The probe is inserted into the agitated suspension with an inclination of $45^{\circ}$ using a dedicated stand (Lasentec $\AA$ ). The data analysis software gives the CLDs in real time according to 100 predefined logarithmic size classes from $1 \mu \mathrm{m}$ to more than $1 \mathrm{~mm}$.

\section{RESULTS AND DISCUSSION}

The raw CLD measured by FBRM can be weighted according to eq. (2):

$$
n_{i, p}=n_{i, 0} c_{i}^{p}
$$

Heath et al. (2002) reported that the square-weighted CLD, as well as the mean square-weighted chord lengths gave data comparable to those given by 
conventional sizing techniques. The square-weighted mean chord length is defined as a Sauter mean diameter as shown by eq. (3). The term Sauter mean crystal size will be used in the following sections to indicate the square-weighted mean chord length.

$$
\bar{L}=\frac{\sum n_{i, 3}}{\sum n_{i, 2}}
$$

\subsection{Effects of storage temperature and duration}

The evolution of Sauter mean ice crystals size with storage time and temperature at a temperature oscillation of $\pm 2.5^{\circ} \mathrm{C}$ is shown on Figure 1 for ICA. A significant increase of mean size of the ice crystals population can be observed as storage temperature and duration augmented. But an asymptotic evolution seems to take place at the end of storage time. Indeed, it can be seen on Figure 1 that the increase in mean crystals size from the beginning to the end of storage were of $282 \%$, $222 \%, 158 \%$ and $105 \%$ respectively for storage temperatures of $-5^{\circ} \mathrm{C},-8^{\circ} \mathrm{c},-12^{\circ} \mathrm{C}$ and $-18^{\circ} \mathrm{C}$ at $\pm 2.5{ }^{\circ} \mathrm{C}$ of temperature fluctuation. However, this size growing seems to slow down from 100 days of storage with only $27 \%, 24 \%, 20 \%$ and $10 \%$ of raise respectively for storage temperatures of $-5^{\circ} \mathrm{C},-8^{\circ} \mathrm{C},-12^{\circ} \mathrm{C}$ and $-18^{\circ} \mathrm{C}$. Similar behaviours were found at $\pm 0.75{ }^{\circ} \mathrm{C}$ and $\pm 0.1{ }^{\circ} \mathrm{C}$ of temperature fluctuations and for ICB (not represented here). These results gave evidence of a higher recrystallization in ice cream exposed to higher temperatures and long term storage. Donhowe and Hartel (1996b) reported similar results about ice cream stored in containers between -15 and $-5^{\circ} \mathrm{C}$ and ice crystal size analyzed by cold stage microscopy and image analysis.

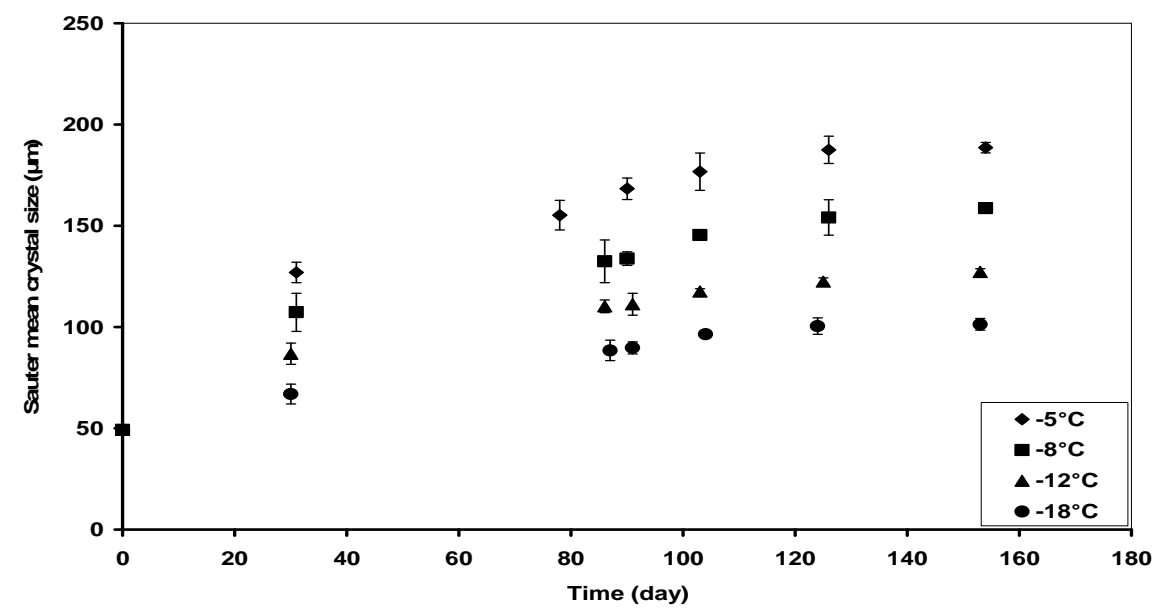

Figure 1. Effects of storage temperature and duration on Sauter mean ice crystals size in ICA stored at $\pm 2.5^{\circ} \mathrm{C}$ of amplitude of fluctuation

\subsection{Effect of amplitude of temperature fluctuations}

Figure 2 compared typical changes on Sauter mean ice crystals size with temperature fluctuations at $-5^{\circ} \mathrm{C}$ and after 103 days storage of both ICA and ICB. Mean ice crystals size augmented as temperature fluctuations increased, for both 
ice creams. The same evolutions were found for the other storage duration even they were not shown here. The effect of amplitude of temperature fluctuations on ice crystal size increasing was more important at high storage temperature. For ICA stored at $-5^{\circ} \mathrm{C}$, the increase in crystal size was equal to $31 \%$ when temperature fluctuations were increased from $\pm 0.1{ }^{\circ} \mathrm{C}$ to $\pm 2.5{ }^{\circ} \mathrm{C}$, and only $24 \%$ at $-18^{\circ} \mathrm{C}$. Similar variations were observed in ICB, but with a smaller extent $(19 \%$ of increase at $-5^{\circ} \mathrm{C}$ and $17 \%$ at $-18^{\circ} \mathrm{C}$ ). Higher recrystallization rates were also found at oscillating-temperature storage by Donhowe and Hartel (1996a; 1996b).

It can also be seen on Figure 2 that the mean crystal size of the ICA is significantly larger than the one of ICB. It is also shown that the recrystallization rate is greater in the ICA than in ICB. Mean ice crystal size increased from $96.5 \mu \mathrm{m}$ to $176.7 \mu \mathrm{m}$ for ICA when temperature increased from $-18^{\circ} \mathrm{C}$ to $-5^{\circ} \mathrm{C}$, corresponding to a size increase of $83 \%$. This increase is only of $45 \%$ for ICB with mean ice crystal size increasing from $60.8 \mu \mathrm{m}$ to $88.5 \mu \mathrm{m}$.

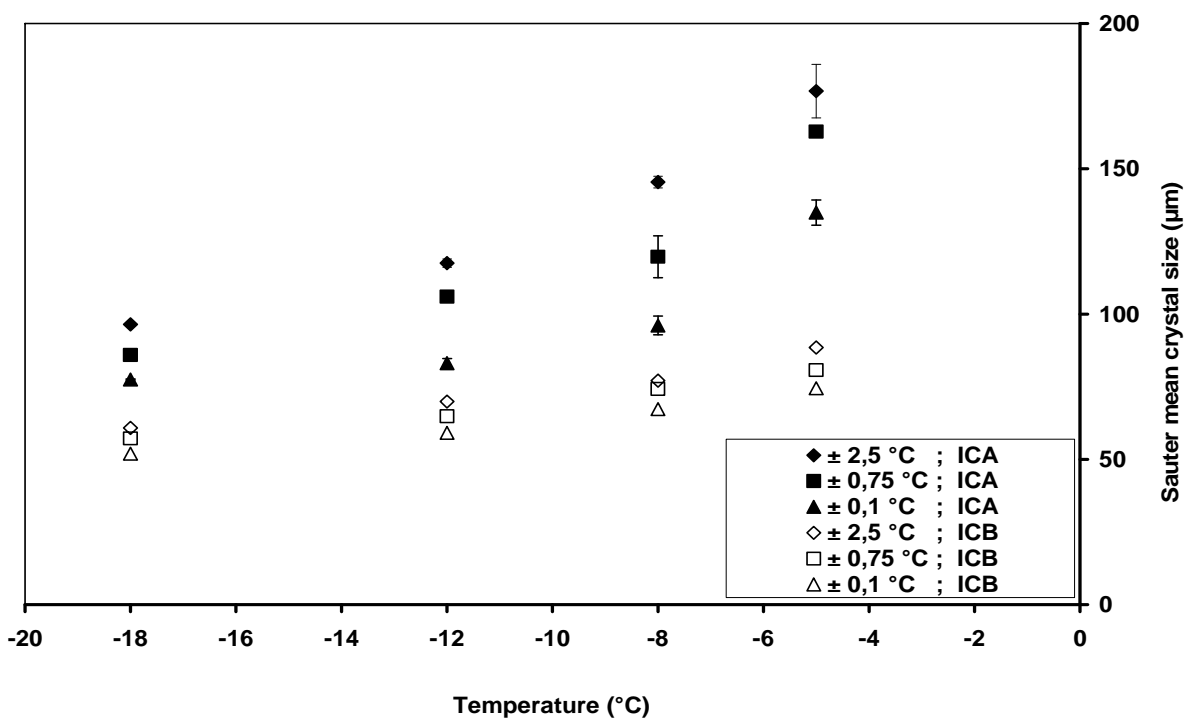

Figure 2. Effect of amplitude of temperatures fluctuation Sauter mean crystals size after 103 days of storage of ICA and ICB

\subsection{Recrystallization kinetics}

Experimental mean size data were fitted to the Ostwald ripening equation (eq. (1)) using a mean value of $n=3$ ( $n$ were found between 1.3 and 4.3 ) as a first approximation in order to allow comparison of recrystallization rates $k$ between the two ice creams and between the three different amplitudes of temperature fluctuation. Mean ice crystal size data fitted $t^{1 / 3}$ kinetics well with regression coefficients varying between 0.809 and 0.975 for ICA and from 0.931 to 0.998 for ICB. Recrystallization rates data were obtained from slopes of plots of Sauter mean crystals size as a function of $\mathrm{t}^{1 / 3}$. These data of $k$ were fitted to the Arrhenius kinetic equation and good representations were obtained $\left(R^{2}=0.881-0.993\right.$ for ICA and $0.982-0.999$ for ICB). The apparent activation energies of recrystallization were fairly similar for all data sets varying from 45109 to $48102 \mathrm{~kJ} \mathrm{~mol}^{-1}$ for ICA. More

$3^{\text {rd }}$ IIR International Conference on Sustainability and the Cold Chain, London, UK, 2014 
variations were found for ICB according to the amplitude of temperature fluctuation with activation energies values between 38371 and $57962 \mathrm{~kJ} \mathrm{~mol}^{-1}$. In order to find one function that describes $k$ at any ice cream mean temperature and amplitude of fluctuations in the range that were studied, mean values of $46283 \mathrm{~kJ}$ $\mathrm{mol}^{-1}$ and $47629 \mathrm{~kJ} \mathrm{~mol}^{-1}$ were used respectively for ICA and ICB. For each ice cream, Arrhenius pre-exponential factors were expressed in function of the amplitude of temperature fluctuation $\Delta T$. Knowing $T$ and $\Delta T, k=f(T, \Delta T)$ can be found from equations (4) for ICA and (5) for ICB, valid for $T$ from $-18^{\circ} \mathrm{C}$ to $-5^{\circ} \mathrm{C}$ and for $\Delta T$ from $0.2^{\circ} \mathrm{C}$ to $5^{\circ} \mathrm{C}$.

$$
\begin{aligned}
& k=\left(2.3710^{9} \Delta T+1.5810^{10}\right) \exp \left(\frac{-46283}{R T}\right) \\
& k=\left(1.60210^{9} \Delta T+1.15410^{10}\right) \exp \left(\frac{-47629}{R T}\right)
\end{aligned}
$$

Figure 3 compares the temperature dependence of ice recrystallization rates in ICA and ICB. Recrystallization rates were found to increase rapidly as the storage temperature and the amplitude of temperature fluctuations increase.

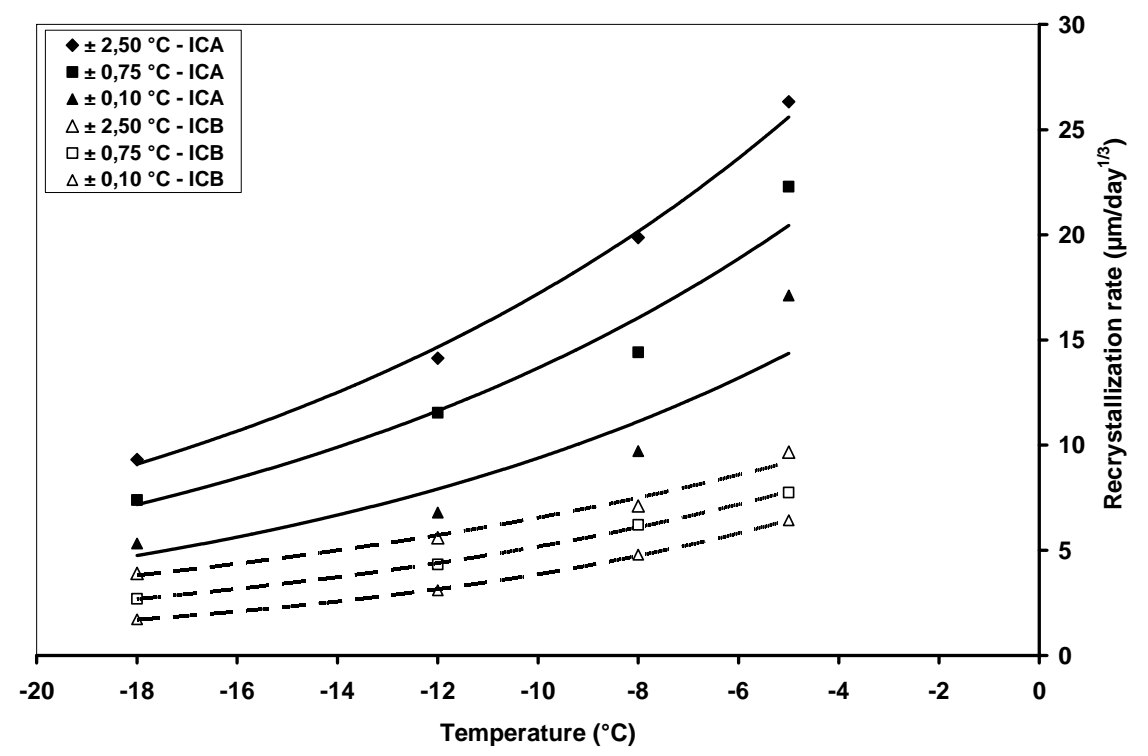

Figure 3. Evolution of recrystallization rate of ice crystals with storage temperature and amplitude of temperatures fluctuation for the two ice creams

Figure 3 clearly shows, as already mentioned, that ice crystal growth was retarded in ICB in comparison with ICA. This result can be attributed to the difference in the formulation of ice creams, especially by the type of stabilizer: LBG as primary stabilizer for ICA and carrageenan for ICB. Different stabilizers have different cryoprotective functionality, probably because of differences in structure. Regand and Goff (2003) found that LBG and carrageenan was both capable to form gellike networks in ice cream model systems (sucrose solutions containing milk protein) retarding water mobility through steric hindrance and water holding. They 
also reported that carrageenan was more effective than LBG in slowing down ice recrystallization, as found in this work where a lower recrystallization rate is obtained in ICB formulated with carrageenan as primary stabilizer. Soukoulis et al. (2008) and more recently BahramParvar et al. (2013) reported that the presence of carrageenan as secondary stabilizer enhance the cryoprotective function of the primary stabilizers. They attributed this effect to the ability of carrageenan to link with caseins leading to a stronger gel network. The use of carrageenan as primary stabilizer may promote a greater viscosity of the liquid phase than LBG due to protein/polysaccharides interactions (Camacho et al., 1998; Yaseen et al., 2005). So, the fact that a lower crystal growth rate was obtained with ICB might be explained by the combined effects of an increased viscosity and a stronger gel structure which reduce the water mobility around ice crystals. This would promote redeposition of water onto the same crystal, rather than diffusion of that water through the unfrozen phase for redeposition onto the largest crystal, which would be thermodynamically favoured. Moreover, this water mobility seems to increase during temperature cycling, resulting in higher recrystallization rates for both types of ice cream. Regand and Goff (2003) have suggested that the water holding capacity of the stabilizer is reduced during temperature cycling, increasing the water mobility around ice crystals due to the continuous shrinking of the rigid gellike structure at every cycle.

\section{CONCLUSION}

The application of FBRM technique to assess recrystallization phenomena in stored ice creams was successfully achieved. The use of FBRM has contributed to improve the speed and the reproducibility of ice crystal size measurements in ice cream. Ice crystals size grew up with mean storage temperature and amplitude of fluctuation of temperatures, for the two differently formulated ice creams studied. Recrystallization rates increased with storage duration, but there appeared to reach a plateau after 100 days of storage for both ice creams regardless the formulation. FBRM has also succeeded to show the significant difference in recrystallization rates according to the formulation, especially the type of stabilizer. Ice crystal sizes in function of storage duration measured by FBRM were fitted with the Ostwald ripening model and kinetic parameters were derived. Further works will be devoted to the validation of this kinetic model. The model will be integrated to a numerical tool for the prediction of ice cream quality for different time/temperature histories throughout the cold chain.

\section{NOMENCLATURE}

$\begin{array}{clcl}c & \text { crystal chord length }(\mathrm{m}) & n_{i, p} & p \text { weighted counts number } \\ k & \text { recrystallization rate }\left(\mathrm{m} \mathrm{s}^{-1}\right) & p & \text { exponent in eq. }(2) \\ \bar{L} & \text { mean crystal size }(\mathrm{m}) & R & \text { gas constant }=8.314 \\ \bar{L}_{0} & \text { initial mean crystal size }(\mathrm{m}) & t & \text { time }(\mathrm{s}) \\ n & \text { power-law exponent in eq. (1) } & T & \text { temperature }(\mathrm{K})\end{array}$

$3^{\text {rd }}$ IIR International Conference on Sustainability and the Cold Chain, London, UK, 2014 


\section{REFERENCES}

Aleong, J. M., Frochot, S. \& Goff, H. D. 2008, Ice Recrystallization Inhibition in Ice Cream by Propylene Glycol Monostearate, Journal of Food Science, 73 (9): E463-E468.

Arellano, M., Benkhelifa, H., Flick, D. \& Alvarez, G. 2012, Online ice crystal size measurements during sorbet freezing by means of the focused beam reflectance measurement (FBRM) technology. Influence of operating conditions, Journal of Food Engineering, 113 (2): 351-359.

BahramParvar, M., Mazaheri Tehrani, M. \& Razavi, S. M. A. 2013, Effects of a novel stabilizer blend and presence of $\kappa$-carrageenan on some properties of vanilla ice cream during storage, Food Bioscience, 3 (0): 10-18.

Caldwell, K. B., Goff, H. D. \& Stanley, D. W. 1992, A low temperature scanning electron microscopy study of ice cream. II. Influence of selected ingredients and processes, Food Structure, 11 11-23.

Camacho, M. M., Martínez-Navarrete, N. \& Chiralt, A. 1998, Influence of locust bean gum $/ \lambda$-carrageenan mixtures on whipping and mechanical properties and stability of dairy creams, Food Research International, 31 (9): 653-658.

Donhowe, D. P. \& Hartel, R. W. 1996a, Recrystallization of ice in ice cream during controlled accelerated storage, International Dairy Journal, 6 (11-12): 1191-1208.

Donhowe, D. P. \& Hartel, R. W. 1996b, Recrystallization of ice during bulk storage of ice cream, International Dairy Journal, 6 (11-12): 1209-1221.

Flores, A. A. \& Goff, H. D. 1999, Recrystallization in Ice Cream After Constant and Cycling Temperature Storage Conditions as Affected by Stabilizers, Journal of Dairy Science, 82 (7): 1408-1415.

Hagiwara, T., Sakiyama, T. \& Watanabe, H. 2009, Estimation of Water Diffusion Coefficients in Freeze-Concentrated Matrices of Sugar Solutions Using Molecular Dynamics: Correlation Between Estimated Diffusion Coefficients and Measured Ice-Crystal Recrystallization Rates, Food Biophysics, 4 (4): 340-346.

Heath, A. R., Fawell, P.D., Bahri, P.A., Swift, J.D. 2002, Estimating Average Partcle Size by Focused Beam Reflectance Measurement (FBRM), Part. Part. Syst. Charact., 19 84-95.

Ndoye, F. T., Erabit, N., Flick, D. \& Alvarez, G. 2013, In-line characterization of a whey protein aggregation process: Aggregates size and rheological measurements, Journal of Food Engineering, 115 (1): 73-82.

Regand, A. \& Goff, H. D. 2003, Structure and ice recrystallization in frozen stabilized ice cream model systems, Food Hydrocolloids, 17 (1): 95-102.

Soukoulis, C., Chandrinos, I. \& Tzia, C. 2008, Study of the functionality of selected hydrocolloids and their blends with $\kappa$-carrageenan on storage quality of vanilla ice cream, LWT - Food Science and Technology, 41 (10): 1816-1827.

Yaseen, E. I., Herald, T. J., Aramouni, F. M. \& Alavi, S. 2005, Rheological properties of selected gum solutions, Food Res. Int., 38 (2): 111-119. 